\title{
The South African perspective on the lean manufacturing Respect for People principles
}

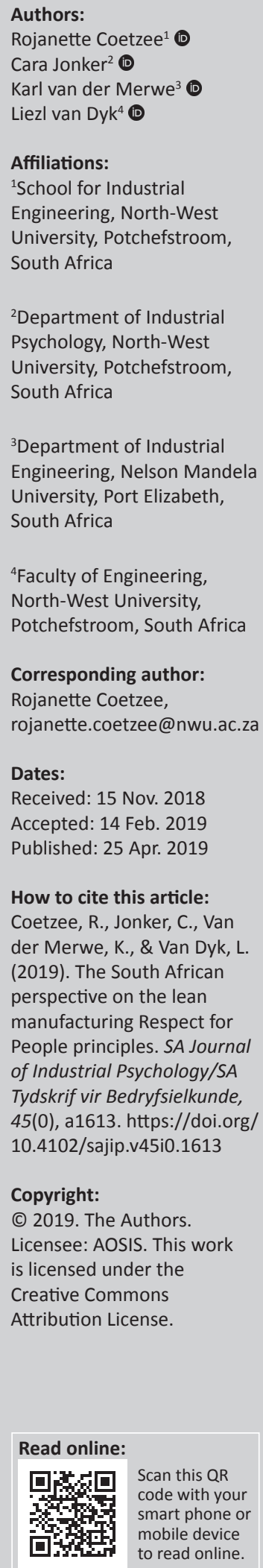

Orientation: Many industries have adopted the popular continuous improvement (CI) approach, lean manufacturing, to facilitate CI initiatives. However, several studies have confirmed that the low success rate of lean implementation can be attributed to the disproportionate focus on lean tools and techniques at the expense of the human factor, as expressed in the Respect for People (RFP) principles mentioned in lean literature.

Research purpose: To provide qualitative insight into the understanding and applicability of the Japanese RFP principles within the South African context.

Motivation for the study: An improved understanding of these RFP principles within the South African context can contribute to more successful lean implementations.

Research approach/design and method: A phenomenological approach was followed to conduct the study in different South African industries. Purposive, expert sampling was used and 22 individuals took part in the exploratory discussions. Data analysis was performed using applied thematic analysis.

Main findings: The South African participants identified all the Japanese RFP principles as applicable to the South African context. However, additional RFP themes were also identified, specifically job security and aligned commitment.

Practical/managerial implications: These findings are of importance to organisations planning to implement a Japanese-designed optimisation technique within a South African context. Organisations should pay attention to the original Japanese RFP themes and the additional RFP themes identified in this study.

Contribution/value-add: This study contributes to the limited research available on lean manufacturing and the RFP principles within the South African context. New RFP themes are provided for organisations implementing a Japanese CI methodology within a South African context. The comparison of the understanding of the RFP themes in Japan and South Africa also contributes to the field of industrial psychology.

Keywords: Lean manufacturing; respect for people; applied thematic analysis; thematic map; continuous improvement; Japanese.

\section{Introduction}

Organisations are pressured to implement and adopt new continuous improvement (CI) approaches to enhance their efficiency and competitiveness (Kwahk \& Lee, 2008; Losonci, Demeter, \& Jenei, 2011; Nordin, Deros, Wahab, \& Rahmand, 2012). Shifts in customer demand, an increased variety of products and demand, and the quest for perfect quality are driving these changes (Anand \& Kodali, 2010). Several organisations and industries across the globe have adopted the popular CI approach, lean manufacturing, to facilitate these required CI changes (Losonci et al., 2011).

During the 1980s, the automotive industry attracted attention when it became apparent that Japanese cars were lasting longer than American cars and required less maintenance (Liker, 2004). The production system used by Toyota was appropriately named the Toyota Production System (TPS) and Liker (2004) describes it as 'a unique approach to manufacturing' and Toyota's 'manufacturing philosophy'. Professor Liker has been studying Toyota for more than 20 years and was given unprecedented access to Toyota executives, employees and factories, both in Japan and in the United States, in order to gain a better understanding of the TPS.

Outside of Toyota, the TPS is known as 'lean' or 'lean production' (Liker, 2004). The lean production movement continued to dominate manufacturing trends along with Six Sigma (a disciplined and 
data-driven approach to eliminating defects) for decades. Toyota popularised several tools and quality improvement methods, but tools and techniques alone do not work as secret weapons to transform a business. The human factor also has to be taken into consideration. Liker (2004) clearly states that Toyota's continued success at implementing these tools stems from a deeper business philosophy based on its understanding of people and human motivation.

The relationship between the social and technical components of a lean manufacturing system is complex and determines the overall system performance in the short and long term (Gaiardelli, Resta, \& Dotti, 2018). Tsutsui already recognised this in 1998, stating that production management consists of both technological and human elements. According to him, the development of the TPS was a monumental achievement in the history of production management, as it proposed a whole new method of analysing both these elements simultaneously as part of one system. This was crucial as it recognised human resources as part of the strategy to be applied for a competitive advantage.

Figure 1 depicts the Toyota Way model as presented in the company's internal documents. The model is centred on two principles: Continuous Improvement (CI) and Respect for People (RFP), which, in turn, are built on three and two foundational blocks, respectively (Liker \& Hoseus, 2008). Continuous Improvement is built on challenge (identify a long-term vision that meets challenges with courage and creativity to realise dreams), kaizen (improve business operations continuously, always striving for innovation and evolution) and Genchi Genbutsu (a Japanese word for going to the source of the problem to find the facts and to make correct decisions, build consensus and achieve goals at the best speed). The second pillar, RFP is built on respect (respect each other, make every effort to understand each other, take responsibility and build mutual trust) and team work (stimulate personal and professional growth, share the opportunities of development and maximise individual and team performance).

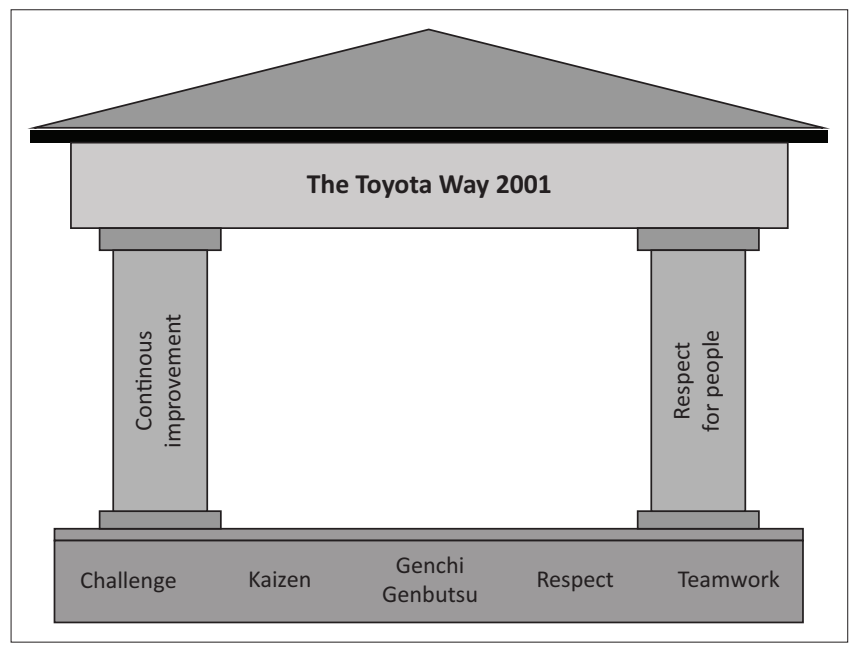

Source: Liker, J. K., \& Hoseus, M. (2008). Toyota culture. New York: McGraw-Hill FIGURE 1: Toyota Way 2001.
It is clear from the pillars of the house that CI cannot be accomplished without RFP. Taiichi Ohno (1988), the developer of the TPS, emphasised this when he stated that respect for humanity is the foundation of the TPS (Womack, Jones, \& Roos, 1990).

However, as Toyota expanded their operations throughout the world to countries such as South Africa, they encountered cultural challenges, as the Toyota Way is deeply rooted in the Japanese culture (Liker \& Hoseus, 2008). There are differences in the way people reason in the East and in the West (Liker \& Hoseus, 2008). People in the West tend to see lean (incorrectly) as a toolkit that can help control the workplace to achieve specific measurable objectives. In the western world, people also objectify the workplace by seeing simple cause-andeffect relationships, while losing sight of the people and the complex dynamics of the environment (Liker \& Hoseus, 2008). Contrary to this, when a Toyota sensei looks at improving the workplace, they do not see a number of independent variables that can be manipulated. They rather see a number of people who work together in a process that is filled with waste (Liker \& Hoseus, 2008).

The RFP principles are key to making the lean management system work (Marksberry, 2011). However, lean management practitioners do not understand this correctly if they are trying to implement lean manufacturing by focussing mostly on the CI of processes, while ignoring or misunderstanding the Respect for People pillar (Cardon \& Bribiescas, 2015; Emiliani, 2006; Emiliani \& Stec, 2005; Taleghani, 2010). This error in judgement significantly limits the improvement that can be achieved by lean implementation, as it is the RFP pillar that enables CI initiatives to be successful and sustainable (Emiliani, 2006).

Several research studies also confirm that a contributing factor to the low levels of success for lean implementation is the disproportionate focus on lean tools and techniques at the expense of the human side of lean management (Bhasin, 2012; Cardon \& Bribiescas, 2015; Coetzee, Van der Merwe, \& Van Dyk, 2016; Gao \& Low, 2015; Jadhav, Mantha, \& Rane, 2014; Miller, Brom, \& Houge, n.d.; Nordin, Deros, \& Wahab, 2011; Pakdil \& Leonard, 2014). Employees often do not feel valued although they are in the best position to offer suggestions to improve the efficiency of the work they do (Sim \& Rogers, 2008).

This research issue can be addressed by exploring the principles and experiences of lean manufacturing within the South African context. Against this background, the following research questions were formulated:

- Are all the Japanese RFP principles applicable to the South African context?

- Are any additional RFP principles required for lean implementation to be successful within the South African context? 


\section{Research aim and objectives}

This article aims to provide insight into the understanding and applicability of the Japanese RFP principles within the South African context by means of qualitative research. The study adopted an exploratory approach to data collection and interpretation to explain how the human resources pillar must be applied as part of the overall lean manufacturing implementation.

The following literature review will provide more information on the Japanese-developed lean manufacturing approach to $\mathrm{CI}$.

\section{Literature review}

Before the RFP principles were investigated within the South African context, a literature review was conducted on the original RFP themes for lean implementation as developed by the Japanese creators. The literature review also explored the five-phase problem-solving process included in the Toyota Way and the eight forms of waste mentioned in lean literature.

As the study followed an inductive approach, the literature was consulted with caution in the early stages to prevent the researcher's analytical field of vision from being narrowed (Braun \& Clarke, 2006; Guest, MacQueen, \& Namey, 2012).

\section{Problem-solving process}

A big part of CI is to solve problems regularly. The Toyota Way refers to the following specific five-phase problemsolving process to address such problems (Womack, 2008):

1. The first step is for the manager to ask the employee about the problem that the employee is experiencing to determine the 'real' problem, not just the 'surface' problem.

2. The employee is then asked what causes the problem to determine the root cause. The employee should provide evidence from the actual workplace to be investigated in collaboration with the manager.

3. The employee is then asked to propose a solution and provide a reason for the specific solution as opposed to other alternatives.

4. The employee is also asked how they (the employer and employee) will know that the problem is solved. How can it be monitored?

5. Once an agreement is reached on the correct course of action, the employee implements it.

This problem-solving process represents the highest form of respect (Emiliani, 2008; Womack, 2008): The manager admits that he cannot solve a particular problem alone as he does not know all the facts. Moreover, the manager shows respect for the employees' knowledge and their dedication to finding the best answer to an issue. Ignoring the invaluable inputs that the workers can give is seen as disrespectful
(Stewart, 2012). On the other hand, the employees cannot solve the problems alone, as they are too involved in the process to ask sufficiently critical questions about their own work.

\section{The eight forms of waste}

Within the lean context, the term 'waste' is attributed to all meaningless, non-essential activities that do not add value to the product and that can be eliminated immediately in order to improve an organisation's productivity (Liker, 2004). The eight forms of waste are explained as follows (Liker, 2004):

1. Transportation: Material and parts that are moved around without adding value to the product.

2. Inventory: Anything that is beyond what is required by the customer negatively influences cash flow and wastes valuable floor space.

3. Motion: Examples of unnecessary movement include looking for something, reaching for something and general walking around.

4. Waiting: Waiting includes waiting for material, information, equipment tools, etc.

5. Over-production: Producing anything more than what is required by the customer.

6. Over-processing: Examples of non-value-added processing include reworking and inspection.

7. Defect: Any product that does not conform to customer requirements.

8. Underutilisation of employee's creativity: People are the most important asset of any organisation. Therefore, an organisation should engage people's minds (not just their bodies) in CI.

\section{Respect for People principles}

Respect for People is a broad commitment. 'It means respect for all people, touched by Toyota including employees, customers, investors, suppliers, dealers, the communities in which Toyota has operations and society at large' (Liker \& Hoseus, 2008).

Coetzee, Van Dyk and Van der Merwe (2018) conducted an extensive study to investigate, report and interpret the original meaning of the RFP principles, as intended by their creators. For the study described in this article, these principles were rearranged into themes and sub-themes (Table 1).

\section{Summary}

In order to incorporate the Toyota Way, during a lean implementation, the RFP and CI principles (pillars) need to be followed. The RFP principles were elaborated on, as well as two CI aspects of the Toyota Way, the five-phase problemsolving process and the eight forms of waste.

Following this review of the Japanese literature, the following section explains the research design that was followed to investigate the RFP within the South African context. 
TABLE 1: The original Japanese Respect for People themes.

\begin{tabular}{|c|c|c|c|c|}
\hline \multirow{2}{*}{$\begin{array}{l}\text { Theme } \\
\text { Individual } \\
\text { development }\end{array}$} & \multicolumn{2}{|c|}{ Sub-themes } & \multicolumn{2}{|c|}{ Quotation } \\
\hline & $(1)$ & Value of people & (1) & Ensure people feel appreciated as individuals (Cardon \& Bribiescas, 2015). \\
\hline & $(2)$ & Worker's input & $\begin{array}{l}(1) \\
(2) \\
(3)\end{array}$ & $\begin{array}{l}\text { Create a system through which they can provide ideas (Cardon \& Bribiescas, 2015; Liker, 2004). } \\
\text { Encourage employees to provide ideas on how to improve their work and workplace (Husar, 1991). } \\
\text { Respect not only a person's physical abilities but also their minds and experience (Liker, 2004). }\end{array}$ \\
\hline & (3) & Motivate people & $\begin{array}{l}(1) \\
(2) \\
(3) \\
(4) \\
(5) \\
(6)\end{array}$ & $\begin{array}{l}\text { Set challenging targets for them (Liker, 2004). } \\
\text { Put constant measurements in place to track progress (Liker, 2004). } \\
\text { Provide regular in-progress feedback (Liker, 2004). } \\
\text { Ensure people feel appreciated as individuals (Cardon \& Bribiescas, 2015). } \\
\text { Create a system where workers can take part in making improvements (Sugimori, Kusunoki, Cho, \& Uchikawa, 1977). } \\
\text { Implement a reward system for taking part in the process (Liker, 2004). }\end{array}$ \\
\hline & (4) & Develop people & $\begin{array}{l}(1) \\
(2) \\
(3) \\
(4) \\
(5) \\
(6) \\
(7)\end{array}$ & $\begin{array}{l}\text { Improve employees' skills and abilities (Cardon \& Bribiescas, 2015). } \\
\text { Develop employees' problem identification and solving abilities (Liker \& Hoseus, 2008; Puvanasvaran, Megat, Tang, Muhamad, \& } \\
\text { Hamouda, 2008). } \\
\text { Teach employees multi-level skills such as problem-solving and group development (Husar, 1991; Marksberry, 2011). } \\
\text { Develop employee' ability to think and execute tasks as efficiently as possible (Husar, 1991; Marksberry, 2011). } \\
\text { Stimulate personal and professional growth (Liker \& Hoseus, 2008). } \\
\text { Challenge employees' abilities (Liker \& Hoseus, 2008). } \\
\text { Create opportunities for personal development (Liker \& Hoseus, 2008). }\end{array}$ \\
\hline & (5) & Training & $\begin{array}{l}(1) \\
(2) \\
(3)\end{array}$ & $\begin{array}{l}\text { Provide training on the lean philosophy (Liker, 2004). } \\
\text { Provide training on safety issues (Liker \& Hoseus, 2008). } \\
\text { Provide training on job-related tasks (Cardon \& Bribiescas, 2015; Liker, 2004; Saruta, 2006). }\end{array}$ \\
\hline & (6) & $\begin{array}{l}\text { Employee } \\
\text { responsibilities }\end{array}$ & $\begin{array}{l}(1) \\
(2) \\
(3) \\
(4) \\
(5) \\
(6)\end{array}$ & $\begin{array}{l}\text { Display people's capabilities by entrusting them with more responsibility and authority (Marksberry, 2011; Puvanasvaran et al., } \\
\text { 2008; Sugimori et al., 1977). } \\
\text { Assign new and challenging tasks (Liker, 2004). } \\
\text { Give employees autonomy so that they feel that they have control over the job (Liker, 2004). } \\
\text { Give employees the right to stop the production line when they cannot keep up or detect an error, as it is not the conveyer that } \\
\text { operates men, it is rather the men who should operate the conveyer (Sugimori et al., 1977). } \\
\text { Empower employees to participate in managing and improving their workplaces (Puvanasvaran et al., 2008; Sugimori et al., 1977). } \\
\text { Delegate decisions to people (such as job dispatching and overtime) (Sugimori et al., 1977). }\end{array}$ \\
\hline \multirow[t]{2}{*}{$\begin{array}{l}\text { Group } \\
\text { development }\end{array}$} & (7) & Communication & $\begin{array}{l}(1) \\
(2)\end{array}$ & $\begin{array}{l}\text { Establish dialogues that reach a true level of communication that is followed by cooperation and consideration (Kato, 1981). } \\
\text { Ensure sufficient communication during the problem-solving process (Womack, 2008). }\end{array}$ \\
\hline & (8) & Teamwork & $\begin{array}{l}(1) \\
(2) \\
(3) \\
(4)\end{array}$ & $\begin{array}{l}\text { Implement teamwork as the foundation of the organisation (Liker, 2004). } \\
\text { Maximise individual and team performance (Liker \& Hoseus, 2008). } \\
\text { Create a balance between individual excellence and team effectiveness (Liker, 2004). } \\
\text { Instil a feeling of self-importance in employees (Marksberry, 2011). }\end{array}$ \\
\hline
\end{tabular}

(9) Employee relationships (1) Promote employee relationships by ensuring mutual trust and respect (Emiliani, 2008; Liker, 2004; Marksberry, 2011).

Organisational (10) Safety

Assess people's safety in their daily tasks by reducing/eliminating tasks that are:

development

(1) Dangerous (Sugimori et al., 1977)

(2) Injurious to their health (Sugimori et al., 1977).

(2) Injurious to their health (Sugimori et al., 1977).

(11) Waste reduction Remove the following forms of waste from people's daily tasks:

(1) Defects - people required to rectify mistakes (Liker, 2004; Sugimori et al., 1977; Womack \& Jones, 2003).

(2) Over-production - people producing items no one wants (Liker, 2004; Sugimori et al., 1977; Womack \& Jones, 2003).

(3) Excess inventory - people handling inventories and goods that pile up (Liker, 2004; Sugimori et al., 1977; Womack \& Jones, 2003).

(4) Over-processing - people performing processing steps that are unnecessary (Liker, 2004; Sugimori et al., 1977; Womack \& Jones, 2003).

(5) Unnecessary motion - people moving around (Liker, 2004; Sugimori et al., 1977; Womack \& Jones, 2003).

(5) Unnecessary transportation - people moving goods from one place to another without any purpose (Liker, 2004; Sugimori et al., 1977; Womack \& Jones, 2003).

(7) Waiting - people in downstream activities waiting because upstream activities have not been delivered on time (Liker, 2004; Sugimori et al., 1977; Womack \& Jones, 2003).

(8) Unused employee creativity - people performing monotonous, repetitive operations that can be mechanised, automated and unmanned (Liker, 2004; Sugimori et al., 1977; Womack \& Jones, 2003).

(12) Problem-solving (1) Implement the five-phase problem-solving process (Womack, 2008).

$\begin{array}{ll}\text { process } & \text { (2) Ensure engagement and cooperation of everyone (from } \\ & \text { (3) Ensure sincere efforts to cooperate (Womack, 2008). }\end{array}$

(2) Ensure engagement and cooperation of everyone (from top to bottom) in solving problems (Puvanasvaran et al., 2008).

(4) Ensure sincere efforts to cooperate (Womack, 2008).

(4) Ensure mutual consideration and understanding for other people's positions (Kato, 1981).
(5) Implement learning and teaching as a continuous company-wide process (Liker \& Hoseus, 2008).

Source: Please see the full reference list of the article, Coetzee, R., Jonker, C., Van der Merwe, K., \& Van Dyk, L. (2019). The South African perspective on the lean manufacturing Respect for People principles. SA Journal of Industrial Psychology/SA Tydskrif vir Bedryfsielkunde, 45(0), a1613. https://doi.org/10.4102/sajip.v45i0.1613, for more information

\section{Research design}

\section{Research approach and strategy}

A qualitative research approach was followed to understand how people make sense of the world and how they experience the research questions at hand (Willig, 2013). The study was orientated to collect data that provide contextual information and contribute to understanding the specific phenomena (Sanders, Cogin, \& Bainbridge, 2014). The study also has a constructionist paradigm, as meaning and experience are socially produced and reproduced (De Vos, Strydom, Fouche, \& Delport, 2011). Furthermore, the study was phenomenological in nature, aiming at both understanding and interpreting how participants understood the RFP principles (Creswell, 1994; De Vos et al., 2011; Trochim \& Donnelly, 2008).

\section{Research method}

\section{Research setting}

Qualitative, in-depth interviews were conducted in South Africa to obtain data on the South African perspective on the Japanese RFP principles. As these principles are incorporated in different South African industries (not just the automotive industry), interviews were conducted over a range of different industries, such as health care, precious metals, aviation and manufacturing industries, as well as the academic environment.

\section{Entrée and establishing researcher's role}

The researchers contacted the potential participants by emailing a request for an appointment that would be convenient for them. The email was sent to personal 
acquaintances of the researchers and therefore the response rate was positive.

The researchers planned the study by contacting the participants and arranging the interviews, as well as conducting the interviews and analysing the data. A research assistant was appointed to assist with taking field notes.

\section{Sampling}

The sampling of this qualitative study involved purposive, expert sampling with a relatively small sample size (Trochim \& Donnelly, 2008). The goal was to describe the range of variability and not the distribution across a general population (Guest et al., 2012). The inclusion criteria to participate in the study were known and demonstrable experience and expertise in the area of lean implementation (Trochim \& Donnelly, 2008).

Table 2 provides the frequency distribution of the sample. It is evident that the sample comprised highly educated and experienced people. All participants had a qualification higher than matric, with $50 \%$ having either a master's or doctoral degree. In terms of experience, very few participants $(13.6 \%)$ had fewer than 10 years' experience. Almost half (45.5\%) had between 11 and 20 years' experience and three candidates had between 30 and 50 years of experience. South Africa was represented by participants from the Western Cape (one participant), the North West (two participants), Gauteng (six participants) and the Eastern Cape (59.1\%).

\begin{tabular}{|c|c|c|c|}
\hline Item & Category & Frequency & $\%$ \\
\hline \multirow[t]{8}{*}{ Industry } & Automotive & 9 & 40.9 \\
\hline & Cable manufacturing & 1 & 4.5 \\
\hline & Precious metals & 1 & 4.5 \\
\hline & Lean institutions & 1 & 4.5 \\
\hline & Health care & 1 & 4.5 \\
\hline & Aviation & 2 & 9.1 \\
\hline & Steel manufacturing & 1 & 4.5 \\
\hline & Academia & 6 & 27.3 \\
\hline \multirow[t]{7}{*}{ Organisational level } & Lecturer & 5 & 22.7 \\
\hline & Professor & 1 & 4.5 \\
\hline & Manager & 11 & 50.0 \\
\hline & Senior manager & 2 & 9.1 \\
\hline & Executive manager & 1 & 4.5 \\
\hline & Chairman & 1 & 4.5 \\
\hline & Chief executive officer & 1 & 4.5 \\
\hline \multirow[t]{5}{*}{ Education level } & Bachelor's degree & 6 & 27.3 \\
\hline & B.Tech & 4 & 18.2 \\
\hline & Diploma & 1 & 4.5 \\
\hline & Master's degree & 5 & 22.7 \\
\hline & Doctoral degree & 6 & 27.3 \\
\hline \multirow[t]{5}{*}{ Experience level } & $>1-10$ years & 3 & 13.6 \\
\hline & $11-20$ years & 10 & 45.5 \\
\hline & $21-30$ years & 5 & 22.7 \\
\hline & $31-40$ years & 3 & 13.6 \\
\hline & $41-50$ years & 1 & 4.5 \\
\hline \multirow[t]{4}{*}{ Province in South Africa } & Eastern Cape & 13 & 59.1 \\
\hline & Western Cape & 1 & 4.5 \\
\hline & North West & 2 & 9.1 \\
\hline & Gauteng & 6 & 27.3 \\
\hline
\end{tabular}

The reason for the large contingent from the Eastern Cape was that the largest portion of participants was from the automotive industry (40.9\%), which is situated mostly in the Eastern Cape. The second largest contribution (27.3\%) was from academia.

\section{Data collection method}

A total of 31 individual, exploratory discussions were conducted with a panel of 22 participants. At the start of each interview, the participant was provided with a summary of the RFP principles, as developed by Coetzee et al. (2018). Participants were asked to reflect on the principles and to comment on the following questions:

- Do you think all the RFP principles, as developed by the Japanese creators, are applicable to the South African context?

- Are any additional RFP principles required for lean implementation to be successful within the South African context?

There was no time limit for the interviews. Participants were allowed to discuss any issues or themes as they emerged from the conversation. Interviews varied from $30 \mathrm{~min}$ to $2 \mathrm{~h}$, the average being $1 \mathrm{~h}$.

Any ambiguity that was identified from the transcripts afterwards was clarified with the participants via email or phone calls after the interviews. In some cases, participants made references to internal company documents or procedures without discussing them in detail during the interviews. Permission to see these documents was then requested afterwards via email.

\section{Data recording}

A total of $22.5 \mathrm{~h}$ of interviews were recorded. The interviews were transcribed to ensure that all information was noted for subsequent analysis of the correct meanings and subtleties of the participants' responses. The transcription was done by the researchers and by a professional transcriber and verified by the researchers. More than 450 pages of data were produced from the verbatim transcription process.

The researcher and the assistant took field notes as an additional source. Where the purpose of the transcripts was to capture the verbatim interviews, the field notes were used to record subtler observations, such as body language, facial expression and tone of voice - the 'feeling' of the interview.

\section{Strategies to ensure data quality and integrity}

For the purpose of this study, the term validity refers to the credibility and accuracy of the process and the outcomes associated with the research (Guest et al., 2012). Several procedures were used to strengthen the reliability of the analysis process and other parts of the research process to produce a thematic analysis that is rigorous, transparent and credible. 
During the data collection, the voice recordings were transcribed verbatim in order to ensure a rigorous and systematic analysis (Guest et al., 2012). Although interviews were done in both Afrikaans and English, depending on the participant's preference, transcripts were not translated to prevent any further complexity that could affect either the validity or the reliability of the data.

During the analysis phase, validity was enhanced through the triangulation of the data sources (Guest et al., 2012). The researcher's field notes, the research assistant's field notes and the transcripts from the interview recordings were compared. Combining the data sources offered multiple points of reference, which minimised the intrinsic bias that could have emerged from a single-observer method. An audit trail was kept by documenting the entire data analysis process, for example, data included or excluded and the rationale behind this, and of changes made to the codebook and data reduction techniques (Guest et al., 2012).

During the reporting phase, quotes were used as much as possible (without creating a string of raw text), as they bring the raw data, the participants' own words, to the reader and connect the phenomenological world of the participants with the data summary and interpretation generated by the researcher (Guest \& MacQueen, 2008).

\section{Data analysis}

An inductive analysis of the data was performed with a descriptive and exploratory orientation (Guest et al., 2012). Owing to the exploratory nature of the research, the applied thematic analysis (ATA) technique was used for data analysis (Guest et al., 2012; Jones, Coviello, \& Tang, 2011). Applied thematic analysis is considered to be a rigorous, yet inductive, set of procedures that are designed to identify and examine themes from textual data in a way that is transparent and credible (Guest et al., 2012; Jones et al., 2011).

The purpose of the ATA method was to analyse the data thematically in a systematic way to report patterns (themes) within the data (Braun \& Clarke, 2006; Guest et al., 2012; Renard \& Snelgar, 2016). The method draws from other theoretical and methodological perspectives such as grounded theory and phenomenology (Tuckett, 2005). Applied thematic analysis is an inductive technique to explore new themes that emerge in relation to the research question. It corresponds with the phenomenological approach as it is the participants' 'perception, feeling and livid experiences that are paramount to the objective of the study' (Braun \& Clarke, 2006; Guest et al., 2012). Applied thematic analysis therefore extracts the more useful technique from each theory and method and adapts them to an applied research context.

Contrary to word-based analysis, the thematic analysis required involvement and interpretation from the researcher. Similar to grounded theory and the development of cultural models, thematic analysis moves beyond counting explicit words or phrases and rather focusses on identifying and describing both implicit and explicit ideas within the data (themes) (Braun \& Clarke, 2006). Codes are then developed to represent the identified themes and applied or linked to raw data as summary markers for later analysis (Guest et al., 2012). Contrary to methodologies such as grounded theory, the ATA technique uses quantitative techniques in combination with interpretive and other techniques to confront the research problem (Guest et al., 2012).

Phase 1: Familiarisation with the data: In an effort to gain a general overview of the data, the researchers listened to all the recordings while creating an initial list of ideas or themes in the data. The transcribing process was used as a second round to develop a thorough understanding of the data (Braun \& Clarke, 2006; Renard \& Snelgar, 2016).

Phase 2: Generating initial codes: During this phase, the initial codes were generated and grouped by reading the transcripts (Braun \& Clarke, 2006). Frequently expressed keywords were used as an indication of potential codes (Guest et al., 2012). Therefore, the keyword-in-context technique was used as a starting point for developing the code book. ATLAS. ti was used to create a list of the unique words that reappear in the text, while counting the number of occurrences. The list had 8861 words. Common words with limited semantic value, such as articles, prepositions, modifiers, etc., were removed and only categories that were conceptually relevant to the research objectives were singled out. The list was reduced to 63 words. The list was further reduced as much as possible by combining synonyms into single categories (Guest et al., 2012). As the interviews were conducted in Afrikaans and English, Afrikaans words were combined with their English equivalents. The final list contained 38 items that were used as starting point for the development of the codebook. Further development of the codebook was systematic but iterative, only concluding after the last transcript had been coded. The analysis of the data was not a linear approach, but rather a recursive process in which the researcher moved back and forth as needed through the different phases of the study (Braun \& Clarke, 2006; Guest et al., 2012). As certain codes were only added after the second or third time that they appeared in transcripts, the coding process was repeated, focussing on coding the first transcripts with codes that were added only later during the first round.

Phase 3: Code reduction: Code reduction was performed to sharpen, sort, focus, discard and organise the data so that final conclusions could be drawn and verified (Miles \& Huberman, 1994). A code frequency table was used to investigate the possibility of reducing the number of codes while keeping a record of what happened to each code. Codes that only appeared once or twice and did not add value to the research objectives were either deleted or combined with other codes.

Phase 4: Searching for themes: A theme captures something important about the data in relation to the research question and represents some level of patterned response or meaning 
within the datasets (Braun \& Clarke, 2006). Therefore, different codes were sorted into potential themes and all the relevant coded data extracts were collated within the identified themes. The relationships between codes and themes were considered, illustrating which codes appear together and providing a means of assessing the prominence of the combination (Guest et al., 2012). This phase was concluded with a collection of candidate themes and sub-themes and all data that have been coded in relation to them organised into a candidate thematic map (Renard \& Snelgar, 2016).

Phase 5: Reviewing themes: The candidate themes were reviewed by reading all the collated extracts for each theme and considering whether they form a coherent pattern. Next, the validity of the individual themes was considered in relation to the dataset and by asking whether the proposed thematic map accurately reflects the meanings evident in the dataset as a whole (Guest et al., 2012).

Phase 6: Defining and naming themes: The purpose of the sixth and final phase was to define and refine the final themes and codes by means of the final thematic map (Braun \& Clarke, 2006).

\section{Ethical consideration}

In an effort to ensure a high standard with regard to ethics, participation in the study was entirely voluntary and participants could withdraw at any point during or after the interview. Research participants were informed upfront of the research aims and that information would only be used for research purposes. The data remained confidential and no participants are named in this article. The interviews were not unnecessarily long or intrusive and no questions were sensitive or offensive in nature (Renard \& Snelgar, 2016). Ethics approval was also granted by the researcher's university, giving the researcher permission to conduct the research.

\section{Findings}

An ATA was performed. Patterns emerged from the data collected and these were used to generate sub-themes. These sub-themes were grouped into themes according to the context within which they appeared in the transcripts: (1) individual development - sub-themes pertaining to the development of people, (2) group development - sub-themes pertaining to the improvement of interaction between people and (3) organisational development - sub-themes relevant to the improvement of the organisation as a whole (Table 3 ).

\section{Individual development}

Before a lean implementation can commence, the leadership of the organisation should realise the value of people (sub-theme 1) in the organisation:

'And that is what I say, where respect for people comes in, because the first thing that we did, was tell them that they are important since it is them that are doing the job. Not the directors or the business unit managers. They do the work, they see the problems.' (Participant 02-20, Lecturing Professor)
TABLE 3: Thematic map of the South African Respect for People themes and sub-themes.

\begin{tabular}{ll}
\hline Themes & Sub-themes \\
\hline (1) Individual development & Importance of workers \\
& Workers' input \\
& Motivation and buy-in \\
& Development/empowerment of people \\
& Training responsibility, authority and \\
& accountability \\
& Communication \\
(2) Group development & Teamwork \\
& Employee relationship \\
& Waste reduction \\
(3) Organisational development & Ergonomics and safety \\
& Job security \\
& Aligned commitment \\
& Organisational problem-solving process \\
\hline
\end{tabular}

Participant 01-05 explained that many of the initiatives that managers try fail because they do not value the people side. He considers changing the thinking of managers as the bigger challenge. Participant 02-18 agreed that lean implementation is not something that will just happen by itself:

'They can try it as many times as they like, if that respect for people element is not present, it will fail. Respect for people should be central.' (Participant 01-05, HR Manager)

Participant 02-20 realised the difference and importance of both management and workers. He explained that although there are differences in salaries, both parties are equally important, as the worker cannot exist without management and vice versa. He furthermore explained that trying to separate them does not make sense:

'... and that is where respect for humanity starts - with the people.' (Participant 01-07, Senior Manager)

Once management has realised the importance of people in the organisation, workers' input (sub-theme 2) should also be valued. Participant 01-01 explained that shop floor workers know a great deal more about the process than the managers themselves and that their opinions are often not taken seriously enough.

Participant 01-07 explained that management should not only respect a person's physical abilities but also his mind and experience:

'It is actually considered disrespectful if we do not give you an opportunity to use your experience to solve problems. Respect for man is much bigger than just using a person's motor skills. We need to use his mind as well as his experience, we need to use all five his senses.' (Participant 01-07, Senior Manager)

Once the importance of people and their input has been established, it will be easier for workers to have motivation and buy-in (sub-theme 3) to participate in the lean implementation. Participant 01-02 explained that:

'The RFP pillar is absolutely spot-on, since one cannot do a lean implementation if you do not have employees' buy-in.' (Participant 01-02, Plant Manager) 
Participant 02-20 agrees:

'If changes are forced upon people, they will find a way to sabotage it.' (Participant 02-20, Lecturing Professor)

'Therefore, buy-in is required from the workers, management and the workers' unions in order for lean implementation to be successful.' (Participant 01-07, Senior Manager)

Furthermore, for individual development, participants felt that RFP is shown by developing or empowering employees (Participant 01-07) (sub-theme 4). By analogy of there being techniques and systems for improvement of the production side of the organisation, there should also be techniques and systems:

'... for building the capabilities to enable people to realise their full potential at work.' (Participant 01-11, Lean Institute Africa)

\section{The RFP is in:}

'I am here to develop you as part of my management responsibility.' (Participant 01-11, Lean Institute Africa)

Participant 01-11 was very specific on a certain element of employee development:

'The idea of respect for people comes out in a very deep commitment to develop the subordinate. Now this is the role of the manager, in a tiered fashion, to develop the problem-solving or, in the western world we might use the terminology decisionmaking capabilities, of people as part of your responsibility as manager.' (Participant 01-11, Lean Institute Africa)

Training (sub-theme 5) of employees was also considered an important part of developing employees. If training is not done sufficiently, there will always be questions about how things are done in the organisation:

'So, training is crucial to get this Respect for People off the ground.' (Participant 01-07, Senior Manager)

Once employees have been developed, trained and empowered as individuals, it becomes possible to further show respect by authorising the employee with greater responsibilities (sub-theme 6):

'Respect is where you tell the people on the shop floor that they have the right to stop the production line. And management does not go down and shout at them and ask what they have done. They ask what is wrong, what did you see happen?' (Participant 02-20, Lecturing Professor)

'The advantage of doing this is that people feel that they have ownership and then they improve and develop further, better than most other people. You cannot expect to give people responsibility if you do not develop them.' (Participant 02-15, General Manager)

\section{Group development}

Respect for people is shown in how people communicate (sub-theme 7) with each other (Participant 02-19, Lecturer):

If you are not able to communicate with people, respect people and come to the level of the people and be humble and understand people's problems, you are not going to get anywhere.
The participants explained that RFP is also shown by means of teamwork (sub-theme 8):

'We respect the fact that you might have to take a day off because you are sick, or your wife is sick and that is where teamwork comes in. Then the people that are with you in a team must be trained to do your job as well.' (Participant 01-07, Senior Manager)

Communication and teamwork are used to build employee relationships (sub-theme 9). In order to show respect for employees, managers should interact with people at all levels and not only work through the tiers (Participant 01-01). Managers should also understand their employees beyond their roles as operators. They must even begin to understand their family situations so that when they have problems at home that affect their work, they will understand and be able to assist them (Participant 02-19):

'Respect for people... no matter whether it is a sweeper or the $\mathrm{CEO}$, the respect is there for everybody. So only by speaking to people and getting to know them is it possible to build relationships. Often, human beings judge other people by just looking at them and then making assumptions. But if you do not speak... If you speak and get to know what they are all about and what they are doing, it breaks the ice and they become familiar.' (Participant 02-19, Senior Lecturer)

\section{Organisational development}

For organisational development, ergonomics (sub-theme 10) is considered a way for an organisation to show respect for its people:

'It is considered disrespectful if I let you work too hard physically, un-ergonomically.' (Participant 01-07, Senior Manager)

Lean literature explains eight forms of waste (refer to Literature Review). Although these principles mostly pertain to the technical production side, removing waste (sub-theme 11) from people's everyday life can also be seen as RFP:

'You are disrespectful towards someone if you let him stand and do nothing - idle time. But also, the waste of it - you are paying him, and he is not doing anything. That is considered disrespectful.' (Participant 01-07, Senior Manager)

Furthermore, participant 01-09 explained that people should never lose their jobs because of a lean implementation. Contrary to the original lean culture of RFP, productivity improvements in South Africa often lead to unemployment. This approach to CI extinguishes the remaining employees' enthusiasm about participating in future improvement activities and, consequently, the pace of improvement is reduced. A lean organisation should rather provide job security (sub-theme 12) to all employees:

'Ja, and I see as result of this 'lean thing', nobody has lost their job yet ... This is great man, let's participate. You know, so that is why these types of initiatives ... it's very good because it's covering all of the aspects of respect and trust.' (Participant 01-09, Manager)

Lean implementation can only be successful if there is aligned commitment (sub-theme 13) between the government, the unions and the organisation. They should all have the 
same vision (Participant 01-07). Furthermore, people within the organisation should also have the same goal:

'RFP is about respecting the total human being, because we have the same goal. If we respect each other as colleagues, as coworkers, then we respect each other in such a manner that causes progress for the workers, but also for the organisation.' (Participant 01-07, Senior Manager)

The final sub-theme for organisational development is the organisational problem-solving process (sub-theme 14). Organisations should have a standard process to solve problems (refer to Literature review) and show RFP:

'So that is why these types of initiatives, problem-solving specifically, it's very good because it's covering all of the aspects of respect and trust.' (Participant 01-09, Manager)

\section{Discussion}

\section{Outline of the findings}

The aim of this article was to report on a qualitative study into the understanding and applicability of the Japanese RFP principles within the South African context by means of the following research questions:

- Are all the Japanese RFP principles applicable to the South African context?

- Are any additional RFP principles required for lean implementations to be successful within the South African context?

The original Japanese RFP themes were stated in the section titled 'Respect for People principles'. The RFP themes identified by South African participants during the interviews were explained in the 'Findings' section. In order to answer the research questions, the original Japanese RFP themes are compared to the themes identified by the South African participants (Table 4). The Japanese RFP themes are listed on the left. Each theme is matched with a corresponding South African RFP theme on the right. The numbers on the left correspond with the numbers in section titled 'Respect for People principles', while the numbers on the right correspond with the numbers used in the 'Findings' section.

TABLE 4: Comparison between Japanese Respect for People principles and South African Respect for People principles.

\begin{tabular}{lll}
\hline Themes & Japanese sub-themes & South African sub-themes \\
\hline $\begin{array}{l}\text { Individual } \\
\text { development }\end{array}$ & Value of people & Value of people \\
& Worker's input & Workers' input \\
& Motivate people & Motivation and buy-in \\
& Develop people & Development/empowerment of people \\
& Training & Training \\
& Employee responsibilities & Employee responsibilities \\
Group & Communication & Communication \\
development & Teamwork & Teamwork \\
& Employee relationships & Employee relationships \\
Organisational & Safety & Ergonomics and safety \\
development & Waste reduction & Waste reduction \\
& Problem-solving process & Job security \\
& - & Aligned commitment \\
& - & Organisational problem-solving process \\
\hline
\end{tabular}

For individual and group development, all the Japanese themes were identified by the South African participants. However, for organisational development, two additional themes were added by the South African participants that did not form part of the original Japanese RFP themes, namely - job security and aligned commitment.

The answer to this study's first research question is that all the Japanese RFP principles were identified by the South African participants and are therefore applicable to the South African context. The answer to the second research question is that additional RFP themes are required for successful lean implementation within the South African context and for employees to feel respected.

This study's findings draw attention to the fact that cultural differences have an impact on lean implementation. In the book, Management lessons from Taiichi Ohno (Harada, 2015), Ohno cautions managers implementing lean in other countries that Japan is probably the only country where workers will admit to making mistakes and take responsibility for it: In other countries where workers are not as respected, making a mistake often means losing one's job. That means that no one will own up to or admit mistakes, and that people will hide their friend's mistakes as well. This explanation emphasises the importance of realising the influence that different cultures have on lean implementation. The results confirm this effect when lean is implemented in South Africa.

\section{Practical implications}

These findings are of importance to organisations planning to implement a Japanese optimisation technique within a South African context. Attention should be given to the original Japanese RFP themes and the additional RFP themes that were identified by the South African participants: Providing job security to employees prior to lean implementation and ensuring aligned commitment between the organisation, employees and unions by means of realising the importance of people and valuing their input.

Consequently, incorporating the correct RFP principles within a context outside of Japan, such as South Africa, will increase the possibility of successful lean implementation.

\section{Limitation and recommendations}

A possible limitation to this study could be the sample size. Although the aim was to describe the range of variability and not the distribution across a general population, it could be possible that a larger sample could provide richer data on the South African context.

Although this study focussed on a broad range of different industries in South Africa, it is recommended that future research should be expanded to more industries in South Africa. Furthermore, this article focussed on the primary manufacturing provinces of South Africa. It could be beneficial for future research to include all the provinces. 
In addition, this study focusses on the organisational levels of management and higher. Including the opinions of the lower levels, such as shop floor workers, could add further valuable insights with regard to RFP in the workplace.

\section{Conclusion}

This study has provided insight into lean implementation within the South African context. All the Japanese RFP themes are required for the South African context, but additional themes are also required. South Africans require job security prior to a lean implementation and they believe aligned commitment between employees, company and unions is required for successful lean implementation.

This study provides South African companies with the required RFP themes to implement a Japanese CI methodology within another context. The article contributes to the field of industrial psychology by comparing the understanding of RFP themes in Japan and South Africa.

The focus of further research should be on combining the South African RFP themes with the Japanese RFP themes in an RFP lean implementation model for the South African context.

\section{Acknowledgements}

Financial assistance of Technology and Human Resources for Industry Programme (THRIP), in partnership with Denel Aeronautics, a Division of Denel SOC Ltd, towards this research is hereby acknowledged.

\section{Competing interests}

The authors declare that they have no financial or personal relationships that may have inappropriately influenced them in writing this article. Opinions expressed and conclusions arrived at in this article are those of the authors and are not necessarily to be attributed to the THRIP or Denel SOC Ltd.

\section{Author's contributions}

This manuscript forms part of R.C.'s PhD thesis, and as such, this author took the lead in the research and the writing of the manuscript. C.J., K.V.D.M and L.V.D. were co-promoters and provided conceptual input and guidance in the structuring and writing of the manuscript.

\section{References}

Anand, G., \& Kodali, R. (2010). Analysis of lean manufacturing frameworks. Journal of Advanced Manufacturing Systems, 9(01), 1-30. https://doi.org/10.1142/ Advanced Manufacturin

Bhasin, S. (2012). An appropriate change strategy for lean success. Management Decision, 50(3), 439-460. https://doi.org/10.1108/00251741211216223

Braun, V., \& Clarke, V. (2006). Using thematic analysis in psychology. Qualitative Research in Psychology, 3(2), 77-101. https://doi.org/10.1191/1478088706qp063oa

Cardon, N., \& Bribiescas, F. (2015). Respect for people: The forgotten principle in lean manufacturing implementation. European Scientific Journal, 11(13), 45-61.

Coetzee, R., Van der Merwe, K. R., \& Van Dyk, L. (2016). Lean implementation strategies: How are the Toyota Way principles addressed? South African Journal of Industrial Engineering, 27(3), 79-91. https://doi.org/10.7166/27-3-1641
Coetzee, R., Van_Dyk, L., \& Van_der_Merwe, K. R. (2018). Towards addressing respect for people during lean implementation. International Journal of Lean Six Sigma. https://doi.org/10.1108/IJLSS-07-2017-0081

Creswell, J. (1994). Research design: Qualitative and quantitative approaches. Thousand Oaks, CA: Sage.

De Vos, A., Strydom, H., Fouche, C. B., \& Delport, C. S. L. (2011). Research at grass roots. Pretoria, South Africa: Van Schaik Publishers.

Emiliani, B. (2008). The equally important 'Respect for People' principle. In Real lean: The keys to sustaining lean management (vol. 3). Wethersfield, CT: The CLBM LLC. Retrieved from https://www.researchgate.net/publication/265985726_The Equally_Important_Respect_for_People_PrincipleEmiliani, M. (2006). Origins of lean management in America: The role of Connecticut businesses. Journal of management History, 12(2), 167-184. https://doi.org/10.1108/13552520610654069

Emiliani, M., \& Stec, D. (2005). Leaders lost in transformation. Leadership \& Organization Development Journal, 26(5), 370-387. https://doi.org/10.1108/ 01437730510607862

Gaiardelli, P., Resta, B., \& Dotti, S. (2018). Exploring the role of human factors in lean management. International Journal of Lean Six Sigma. https://doi.org/10.1108/ IJLSS-08-2017-0094

Gao, S., \& Low, S. P. (2015). Toyota Way style human resource management in large Chinese construction firms: A qualitative study. International Journal of Construction Management, 15(1), 17-32. https://doi.org/10.1080/15623599.201 5.1012139

Guest, G., MacQueen, K., \& Namey, E. E. (2012). Applied thematic analysis. Thousand Oaks, CA: Sage.

Guest, G., \& MacQueen, K. M. (2008). Handbook for team-based qualitative research. Plymoth, United Kingdom: AltaMira Press.

Harada, T. (2015). Management lessons from Taiichi Ohno: What every leader can learn from the man who invented the Toyoto Production System, New York: McGraw-Hill.

Husar, M. (1991). Corporate culture: Toyota's secret, competitive advantage. General Motors internal paper. Retrieved from http://www.bobemiliani.com/wp-content/ uploads/2016/08/husar_nummi.pdf

Jadhav, J. R., Mantha, S. S., \& Rane, S. B. (2014). Exploring barriers in lean implementation. International Journal of Lean Six Sigma, 5(2), 122-150. https:// doi.org/10.1108/IJLSS-12-2012-0014

Jones, M. V., Coviello, N., \& Tang, Y. K. (2011). International entrepreneurship research (1989-2009): A domain ontology and thematic analysis. Journal of Business Venturing, 26, 632-659. https://doi.org/10.1016/j.jbusvent.2011.04.001

Kato, S. (1981). My years with Toyota. Nagoya City, Japan: Toyota Motor Sales Co., Ltd.

Kwahk, K.-Y., \& Lee, J.-N. (2008). The role of readiness for change in ERP implementation: Theoretical bases and empirical validation. Information \& Management, 45(7), 474-481.

Liker, J. K. (2004). The Toyota way- 14 management principles. New York: McGraw-Hill. Liker, J. K., \& Hoseus, M. (2008). Toyota culture. New York: McGraw-Hill.

Losonci, D., Demeter, K., \& Jenei, I. (2011). Factors influencing employee perceptions in lean transformations. International Journal of Production Economics, 131(1), 30-43. https://doi.org/10.1016/j.ijpe.2010.12.022

Marksberry, P. (2011). The Toyota way - A quantitative approach. International Journal of Lean Six Sigma, 2(2), 132-150. https://doi.org/10.1108/20401461111135028

Miles, M. B., \& Huberman, M. A. (1994). Qualitative data analysis: An expanded source-book. Thousand Oaks, CA: Sage.

Miller, S., Brom, M., \& Houge, J. (2001). Building a lean enterprise culture. Conference proceedings held at Institute of Industrial Engineers Lean Management Solutions Conference, September 2001, (n.p.). St. Louis, MO: n.p.

Nordin, N., Deros, B. M., Wahab, D. A., \& Rahman, M. N. A. (2012). Validation of lean manufacturing implementation framework using delphi technique. Changes, 8(9), 10.

Nordin, N., Deros, B. M., \& Wahab, D. A. (2011). Lean manufacturing implementation in Malaysian automotive industry: An exploratory study. Operations and Supply Chain Management, 4(1), 21-30.

Ohno, T. (1988). Toyota production system: Beyond large-scale production. New York, OR: Productivity Press.

Pakdil, F., \& Leonard, K. M. (2014). Criteria for a lean organisation: Development of a lean assessment tool. International Journal of Production Research, 52(15), 4587-4607. https://doi.org/10.1080/00207543.2013.879614

Puvanasvaran, A., Megat, M. H. M. A., Tang, S. H., Muhamad, M. R., \& Hamouda, A. M. S. (2008). A review of problem solving capabilities in lean process management. American Journal of Applied Sciences, 5(5), 504-511. https://doi.org/10.3844/ ajassp.2008.504.511

Renard, M., \& Snelgar, R. J. (2016). How can work be designed to be intrinsically rewarding? Qualitative insights from South African non-profit employees. SA Journal of Industrial Psychology, 42(1), 1-12. https://doi.org/10.4102/sajip. v42i1.1346

Sanders, K., Cogin, J. A., \& Bainbridge, H. T. J. (2014). Research methods for human resource management. New York : Routledge.

Saruta, M. (2006). Toyota production systems: The 'Toyota Way' and labourmanagement relations. Asian Business \& Management, 5(4), 487-506. https:// doi.org/10.1057/palgrave.abm.9200198

Sim, K. L., \& Rogers, J. W. (2008). Implementing lean production systems: Barriers to change. Management Research News, 32(1), 37-49. https://doi.org/10.1108/ 01409170910922014 
Stewart, J. (2012). The Toyota Kaizen continuum: A practical guide to implementing lean. London: CRC Press.

Sugimori, Y., Kusunoki, K., Cho, F., \& Uchikawa, S. (1977). Toyota production system and kanban system materialization of just-in-time and respect-for-human system. The International Journal of Production Research, 15(6), 553-564. https://doi. org/10.1080/00207547708943149

Taleghani, M. (2010). Key factors for implementing the lean manufacturing system. Journal of American Science, 6(7), 287-291.

Trochim, W. M. K., \& Donnelly, J. P. (2008). The research methods knowledge base. Mason, $\mathrm{OH}$ : Cengage Learning.

Tsutsui, W. M. (1998). Manufacturing ideology: Scientific management in twentiethcentury Japan. Princeton, NJ: Princeton University Press.
Tuckett, A. G. (2005). Applying thematic analysis theory to practice: A researcher's experience. Contemporary Nurse, 19(1), 75-87. https://doi.org/10.5172/conu. 19.1-2.75

Willig, C. (2013). Introducing qualitative research in psychology. Berkshire, England: Open University Press.

Womack, J., Jones, D. T., \& Roos, D. (1990). The machine that changed the world. New York: Rawson Associates.

Womack, J. P. (2008). Respect for people. Retrieved from http://www.lean.org/ womack/DisplayObject.cfm?o $=755$

Womack, J. P., \& Jones, D. T. (2003). Lean thinking: Banish waste and create wealth in your corporation. New York: Simon \& Shuster, Inc. 